\title{
Current Sensorless Control Algorithm for Single-Phase Three-Level NPC Inverter
}

\author{
Alexander Suzdalenko (Researcher, Riga Technical University - RTU), Janis Zakis (Lead Researcher, RTU), \\ Ingars Steiks (Lead Researcher, RTU)
}

\begin{abstract}
The current measurement is becoming a challenging task in power converters operating at high switching frequencies, moreover traditional control system requires two control loops first (slow) regulates DC-link voltage, second (fast) controls the shape of current, that all together results in complicated transfer function and long transition periods. The current sensorless control (CSC) allows neglecting the mentioned problems. This research for the first time presents the solution of CSC implementation in single-phase three-level neutral point clamped inverter. Mathematical equations were defined for inductor current peaks and transistor conduction time during discontinuous and continuous conduction modes, as well as major problem of current fitting between different voltage levels (consequently with different current peak-to-peak values) was solved, providing two solutions - pre-fitting and post-fitting trajectories. The verification of our theoretical assumptions and analytical equations was confirmed by the simulation analysis. Challenges of real experiments are discussed in the conclusion.
\end{abstract}

Keywords - Sensorless control; Current control; Pulse width modulation inverters.

\section{INTRODUCTION}

New technologies of power electronic switches allow designing switched mode power supplies (SMPS) operating at higher switching frequencies that leads to minimization of reactive components and increase of power density of power converters. However, current measurement becomes new challenge when operates at frequencies above $100 \mathrm{kHz}$. For instance, galvanically isolated current sensors inherit signal's propagation delay as well as limited bandwidth. The use of shunt resistor eliminates the mentioned problems, but on the other hand leads to additional conduction losses that negatively influence the efficiency of the converter. Thus, elimination of instantaneous current measurement would allow overcoming of the mentioned problems as well as reducing the cost and size of the control system, as it has been mentioned in multiple articles [1]-[4].

Moreover, traditional control system usually consists of two control loops - the first one (slow) controls the capacitor voltages on the DC link, while the second one (fast) controls the shape of current. This results in complicated transfer function, as well as in long transient responses, while current sensorless control (CSC) excludes current control loop, that leads to simpler control system of the converter [5], [6].

The CSC method was mostly applied to power factor correction circuit based diode rectifier and boost converter [5]-[7]. Recent publication demonstrated good performance of CSC applied to bidirectional AC/DC converter based on fullbridge converter [8]. All of the mentioned research made their investigation with inductor's continuous conduction mode (CCM) selecting only either bulky inductor or higher switching frequency. Authors' previous publications [9], [10] described the CSC use with half-bridge converter, where among other, the attention is focused also on current control during DCM. Contrary to previous topologies, the inductor in half-bridge converter experiences higher voltage, as a result, current slopes have more impetuous rising and falling edges that leads to longer discontinuous conduction mode (DCM) period, that should not be neglected. The comparison of the mentioned research papers is made in Table I.

For some decades three-level neutral point clamped (NPC) topology has been used in electrical drive applications [11][13], but since the increase of renewable energy applications, NPC has also found its use here [14], [15]. The application of CSC with NPC converters seems relevant, as on one hand inductor is exposed to smaller voltage stresses that provides earlier CCM than, for instance, in full-bridge topology and, as a result, simple CSC calculations. On the other hand, due to switching between different voltage levels, the inductor's current peak-to-peak value changes, which should be specially considered, ensuring that average inductor's current value will track the reference signal. Overviewing the different control techniques of NPC converters [16]-[21], none of them delivers CSC. It is interesting that the sensorless current control discussed in [22], having utilized the sinusoidal carrier-based PWM and having assumed multiple simplifications, has no sense to real CSC.

This paper is organized as follows: the second section introduces the main theory of CSC. The third section demonstrates the simulation results. The last section discusses the results and points out the challenges for real experiments.

TABLE I

COMPARISON OF DIFFERENT CSC PROJECTS

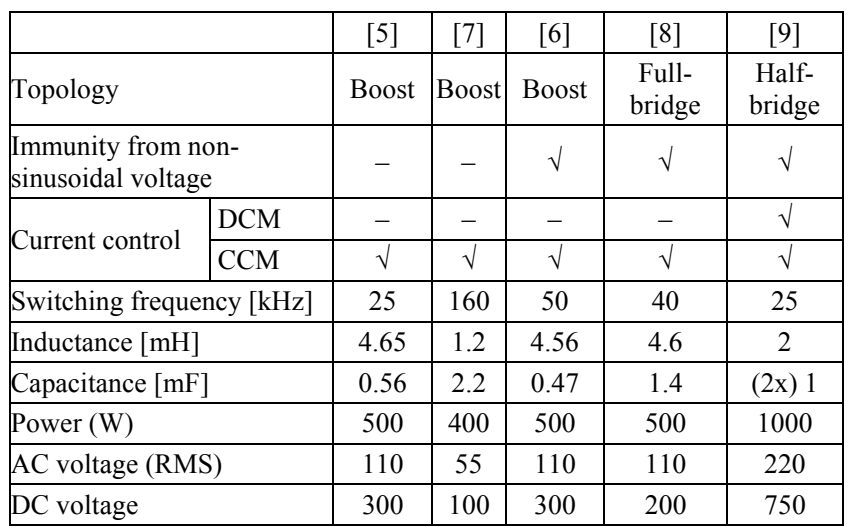




\section{THEORY OF CSC APPLIED FOR MLC}

The main idea of CSC is to hold proper Volts-second balance on inductor, in order to keep average current value to track reference signal. Contrary to full-bridge or half-bridge converters, where either full DC-link voltage or freewheeling state is applied to inductor, the MLC has its superior feature of selecting the voltage level $\left(1 V_{\mathrm{DC}}, 1 / 2 V_{\mathrm{DC}}, 1 / 3 V_{\mathrm{DC}}, 1 / 4 V_{\mathrm{DC}}\right.$ depending on the number of levels) that is applied to inductor. In this research single-phase three-level neutral-point-clamped
(NPC) inverter is studied. Taking into account, that current can be boosted to the grid, when voltage applied to inductor is higher than that of the grid, three combinations of commutated switches have been defined that can be seen in Table II. It demonstrates commutated current paths and corresponding voltage applied to inductor in respect to different input voltage ranges during positive half-period of input voltage. Table III summarizes all switching combinations during the whole period of input voltage.

TABLE II

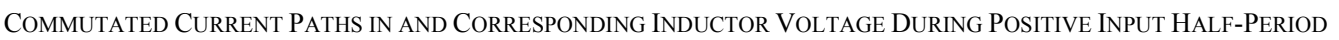

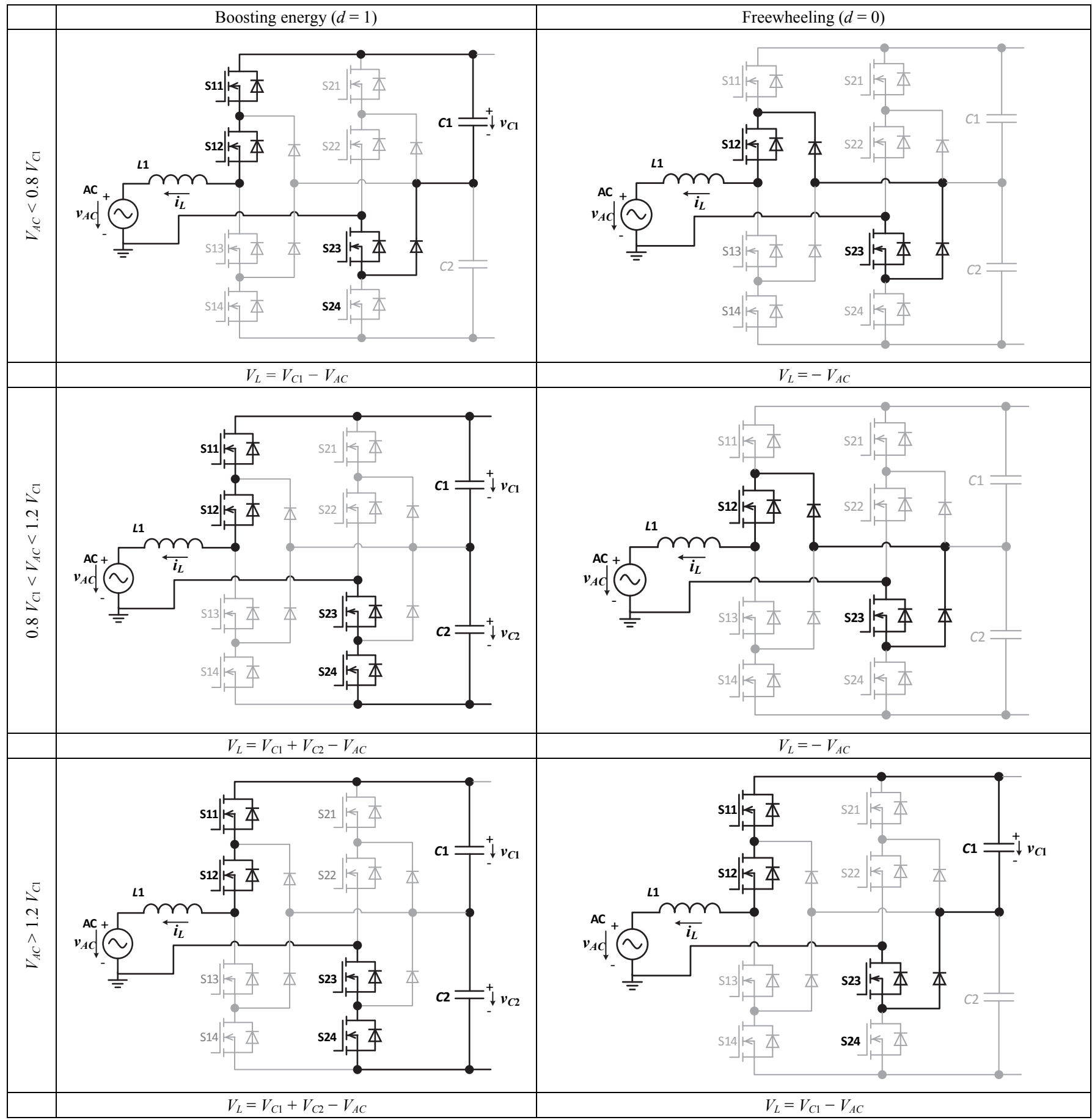


TABLE III

SUMMARY OF SWITCHING SIGNAL COMBINATION AND CORRESPONDING INDUCTOR VOLTAGE

\begin{tabular}{|c|c|c|c|c|c|c|c|c|c|c|c|}
\hline $\begin{array}{l}\text { Input voltage } \\
\text { polarity }\end{array}$ & Input voltage level & $\begin{array}{l}\text { Current path } \\
d(t)\end{array}$ & S11 & $\mathrm{S} 12$ & S13 & S14 & $\mathrm{S} 21$ & S22 & S23 & S24 & Inductor's voltage \\
\hline \multirow{6}{*}{$\begin{array}{l}\stackrel{0}{0} \\
\stackrel{0}{0}\end{array}$} & \multirow{2}{*}{$V_{A C}<0.8 V_{C 1}$} & 1 & 1 & 1 & - & - & - & - & 1 & - & $V_{L}=V_{C 1}-V_{A C}$ \\
\hline & & 0 & - & 1 & - & - & - & - & 1 & - & $V_{L}=-V_{A C}$ \\
\hline & \multirow{2}{*}{$0.8 V_{C 1}<V_{A C}<1.2 V_{C 1}$} & 1 & 1 & 1 & - & - & - & - & 1 & 1 & $V_{L}=V_{C 1}+V_{C 2}-V_{A C}$ \\
\hline & & 0 & - & 1 & - & - & - & - & 1 & - & $V_{L}=-V_{A C}$ \\
\hline & \multirow{2}{*}{$V_{A C}>1.2 V_{C 1}$} & 1 & 1 & 1 & - & - & - & - & 1 & 1 & $V_{L}=V_{C 1}+V_{C 2}-V_{A C}$ \\
\hline & & 0 & 1 & 1 & - & - & - & - & 1 & - & $V_{L}=V_{C 1}-V_{A C}$ \\
\hline \multirow{6}{*}{$\begin{array}{l}\stackrel{0}{己_{0}} \\
\text { ż } \\
\text { ż }\end{array}$} & \multirow{2}{*}{$-V_{A C}<0.8 V_{C 2}$} & 1 & - & - & 1 & 1 & - & 1 & - & - & $V_{L}=V_{C 2}+V_{A C}$ \\
\hline & & 0 & - & - & 1 & - & - & 1 & - & - & $V_{L}=V_{A C}$ \\
\hline & \multirow{2}{*}{$0.8 V_{C 2}<-V_{A C}<1.2 V_{C 2}$} & 1 & - & - & 1 & 1 & 1 & 1 & - & - & $V_{L}=V_{C 1}+V_{C 2}+V_{A C}$ \\
\hline & & 0 & - & - & 1 & - & - & 1 & - & - & $V_{L}=V_{A C}$ \\
\hline & \multirow{2}{*}{$-V_{A C}>1.2 V_{C 2}$} & 1 & - & - & 1 & 1 & 1 & 1 & - & - & $V_{L}=V_{C 1}+V_{C 2}+V_{A C}$ \\
\hline & & 0 & - & - & 1 & 1 & - & 1 & - & - & $V_{L}=V_{C 2}+V_{A C}$ \\
\hline
\end{tabular}

In order to track the changes of polarity of different variables in digital control system, simple Boolean function is defined as follows

$$
\operatorname{pos}(x)=\left\{\begin{array}{l}
0, \text { if } x<0 \\
1, \text { if } x \geq 0
\end{array} .\right.
$$

Now it is possible to write versatile inductor's voltage equations that combine all variation from Table III as follows

$$
\begin{gathered}
v_{L}(d=1)=-\left(2 \operatorname{pos}\left(V_{A C}\right)-1\right) V_{A C}+ \\
+\operatorname{pos}\left(V_{A C}\right) \operatorname{pos}\left(-V_{A C}+0.8 V_{C 2}\right) V_{C 1}+ \\
+\operatorname{pos}\left(-V_{A C}\right) \operatorname{pos}\left(V_{A C}+0.8 V_{C 1}\right) V_{C 2}+ \\
+\left(\operatorname{pos}\left(V_{A C}-0.8 V_{C 1}\right) \operatorname{or} \operatorname{pos}\left(-V_{A C}-0.8 V_{C 2}\right)\right)\left(V_{C 1}+V_{C 2}\right) \\
v_{L}(d=0)=-\left(2 \operatorname{pos}\left(V_{A C}\right)-1\right) V_{A C} \\
+\operatorname{pos}\left(V_{A C}-1.2 V_{C 1}\right) V_{C 1}+\operatorname{pos}\left(-V_{A C}-1.2 V_{C 2}\right) V_{C 2}
\end{gathered} .
$$

Fig. 1 demonstrates discontinuous and continuous current modes for input inductor that also has certain influence on average current calculation equations.

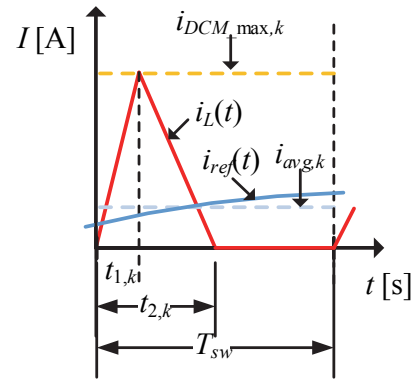

(a) DCM

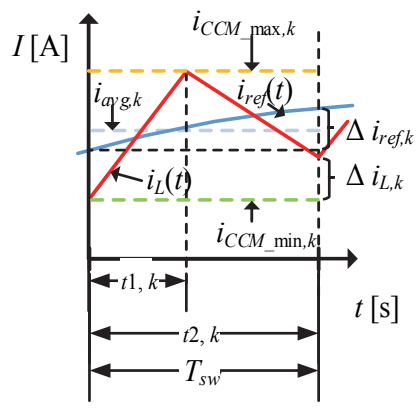

(b) $\mathrm{CCM}$
Fig. 1. Inductor's discontinuous and continuous current modes.

The peak value of inductors current can be described with two formulas as follows

$$
\begin{gathered}
i_{D C M_{-} \max , k}=\frac{V_{L, k}(d=1)}{L} t_{1, k}, \\
-i_{D C M_{-} \max , k}=\frac{V_{L, k}(d=0)}{L}\left(t_{2, k}-t_{1, k}\right),
\end{gathered}
$$

where from $t_{2, k}$ is defined as

$$
t_{2, k}=\frac{V_{L, k}(d=0)-V_{L, k}(d=1)}{V_{L, k}(d=0)} .
$$

The average current can be calculated as simple area of triangle divided by period as follows

$$
i_{\text {ref }, k}=i_{\text {avg }, k}=\frac{i_{D C M_{-} \max , k} t_{2, k}}{2 T_{s w}} .
$$

Substituting the $t_{2, k}$ in (7) by the definition in (6) and extracting transistor's conduction time, the following control law is defined

$$
t_{1, k}=\sqrt{\frac{i_{\text {avg }, k} L 2 T_{s w} V_{L, k}(d=0)}{V_{L, k}(d=1)\left(V_{L, k}(d=0)-V_{L, k}(d=1)\right)}} .
$$

The CCM control law can be extracted from the equation of volt-second balance during single switching period, which is defined as

$$
\Delta i_{r e f, k}=\frac{V_{L, k}(d=1)}{L} t_{1, k}+\frac{V_{L, k}(d=0)}{L}\left(T_{s w}-t_{1, k}\right) .
$$

So, the transistor's conduction time in CCM is defined as

$$
t_{1, k}=\frac{\Delta i_{r e f, k} L-V_{L, k}(d=0) T_{s w}}{V_{L, k}(d=1)-V_{L, k}(d=0)} .
$$

Fig. 2 demonstrates analytical waveforms of DCM and CCM control laws for rectifier and inverter mode. The final commutation signal is selected as minimum value of DCM and CCM signals. 


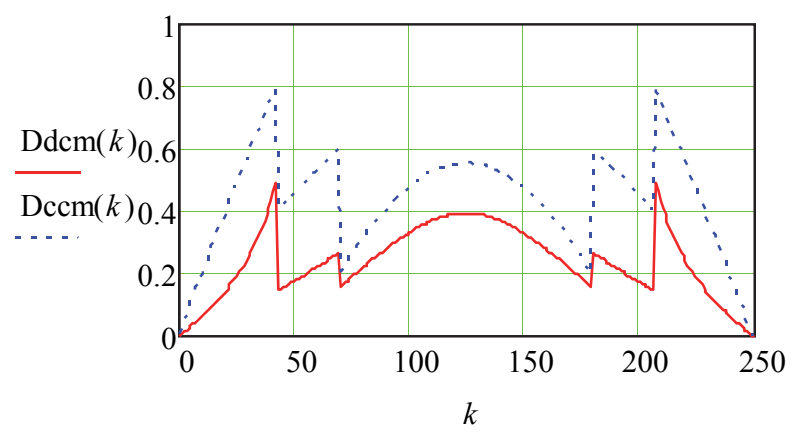

(a) $I_{M}=0.5 \mathrm{~A}$

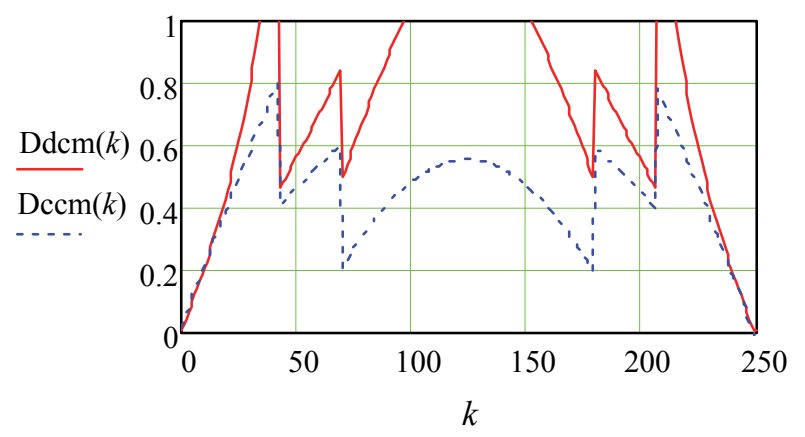

(b) $I_{M}=5 \mathrm{~A}$

Fig. 2. Analytical waveforms of duty cycle for half-period of input voltage (index $k$ represents switching cycle serial number, $f_{A C}=50 \mathrm{~Hz}, f_{S W}=25 \mathrm{kHz}$, $\left.V_{A C \_}=311 \mathrm{~V}, V_{C l}(t=0)=V_{C 2}(t=0)=200 \mathrm{~V}, L=1 \mathrm{mH}\right)$.

Additional attention should be focused on the transition between the different voltage levels during CCM, as peak-topeak current value is also changing. It means that special voltsecond balance should be applied during the transition between different voltage levels switching, in order to keep inductor's average current value to track reference signal. Fig. 3 demonstrates two possible trajectories for current fitting at transition between different voltage levels.

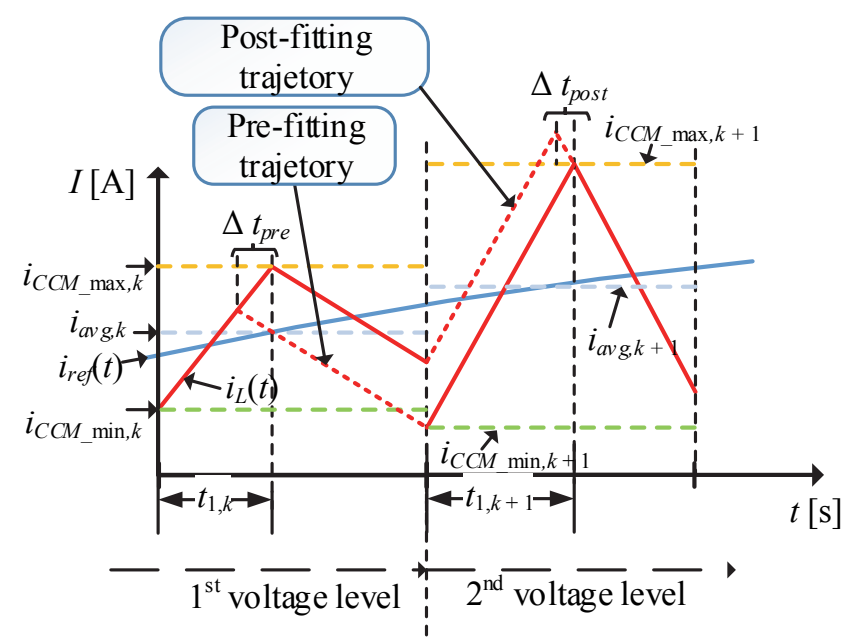

Fig. 3. Options for current fitting at transition between different voltage levels.

Both pre- and post-fitting duty-cycle corrections are calculated by (10), where besides $\Delta i_{\text {ref,k }}$ the differences between current peak-to-peak values (of falling edges) at different voltage levels should be taken into account as follows (equation for post-fitting)

$$
t_{1, k+1}=\frac{\left(\Delta i_{r e f, k+1}-\frac{i_{f a l, k}-i_{f a l, k+1}}{2}\right) L-V_{L, k+1}(d=0) T_{s w}}{V_{L, k+1}(d=1)-V_{L, k+1}(d=0)},
$$

where $i_{f a l, k}$ is calculated similarly as in (5), substituting $t_{2, k}$ with commutation period $T_{S W}$ as follows

$$
i_{f a l, k}=\frac{V_{L, k}(d=0)\left(T_{S W}-t_{1, k}\right)}{L} .
$$

\section{SIMULATION RESULTS}

The PSIM simulation software was used to study the proposed CSC algorithm, which was coded in "Simplified C Block". The open loop control was assembled fast evaluation, as well as voltage sources were used instead of capacitors. The overall schematic is seen in Fig. 4.

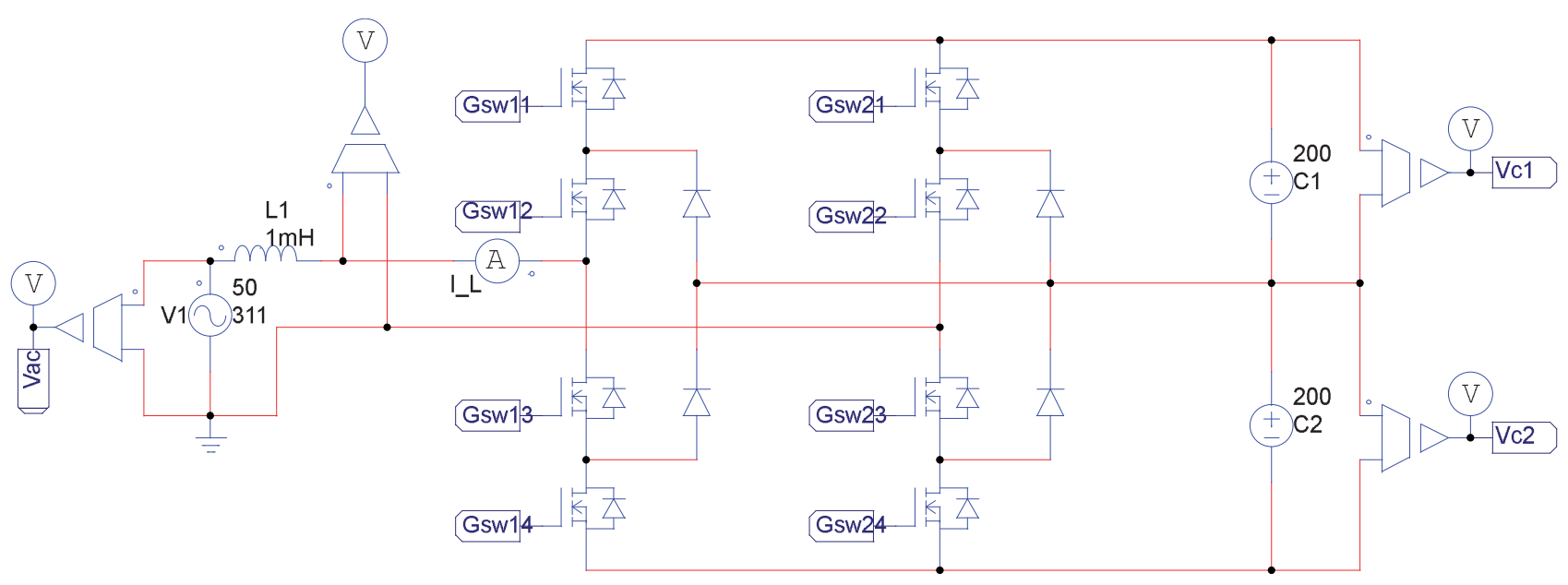

Fig. 4. Power part of the simulation model (ideal elements are utilized). 


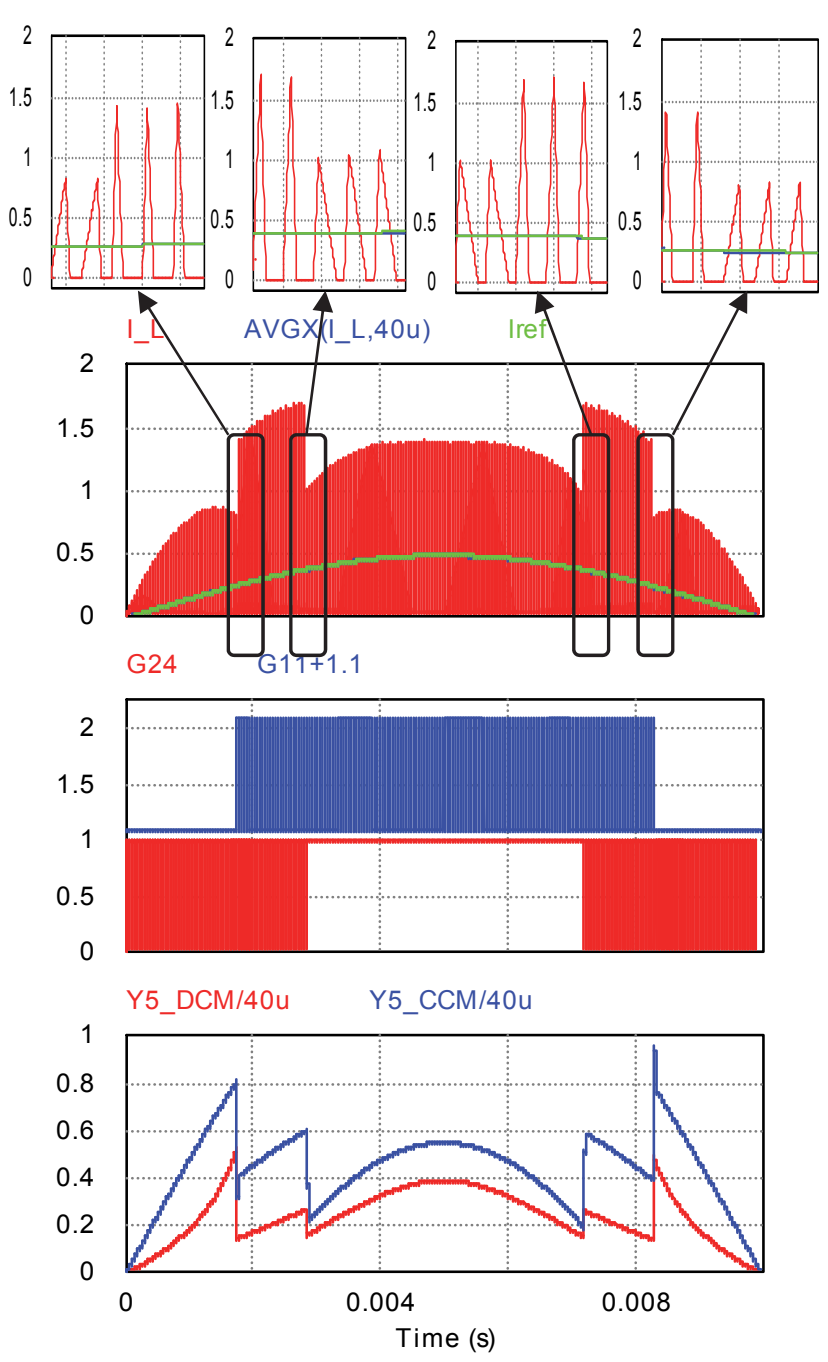

(a) Reference current amplitude $I_{M}=0.5 \mathrm{~A}$
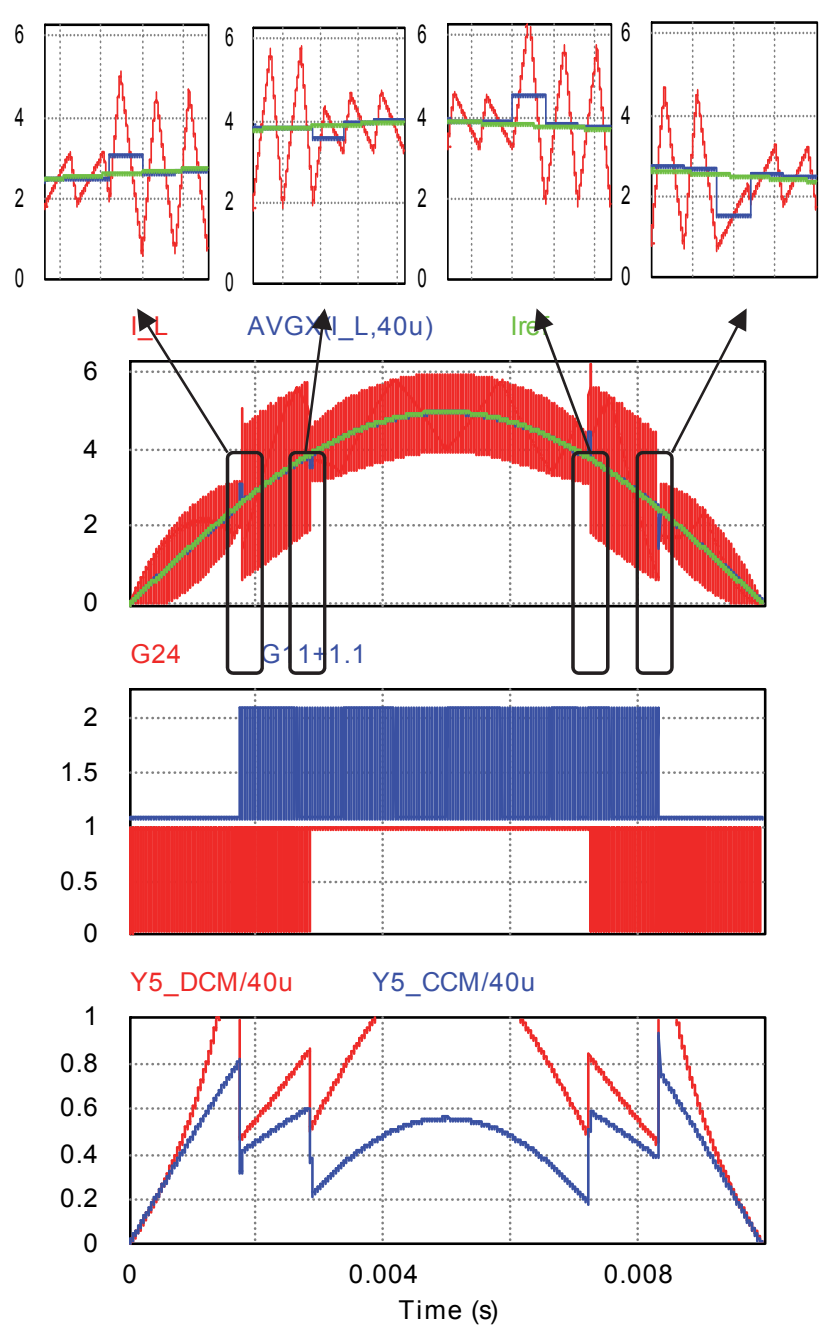

(b) Reference current amplitude $I_{M}=5 \mathrm{~A}$

Fig. 5. Simulation results of CSC applied to NPC inverter during (a) DCM and (b) CCM operation (top graphs (I_L, AVGX(I_L,40u), Iref) consist of inductor's current, average inductor current, reference current values; middle graphs (G24, G11+1.1) contain actively commutated switching signals; bottom graphs represent) calculated DCM and CCM duty cycle values.

Fig. 5 demonstrates the simulation results of NPC inverter operation under CSC algorithm, where duty cycle is calculated by using (8) and (10) and no current control loop is utilized in the control system. As it can be seen from Fig. 5(a) top graph the average value of inductor's current (blue) perfectly matches the reference signal (green). The same can be concluded from Fig. 5(b) top graph, where average inductor's current (blue) matches the reference signal (green), except the switching periods, when transition between different voltage levels occurs. The post-fitting current trajectory has been applied that have provided satisfying results.

\section{CONCLUSION}

The CSC allows eliminating of instantaneous current measurements in SMPS that can be useful for converters operating at high switching frequency and to minimize the cost and size of control system.

Previously this technique was used only with two level SMPS (diode bridge with boost DC/DC converter, half-bridge, full-bridge), while hereby the theoretical model of CSC has been developed for a three-level NPC multilevel inverter, where special attention was focused on proper volt-second balance during the transition between different voltage levels. Two options were defined in this context - pre-fitting and post-fitting current trajectories.

The simulation results confirmed the theoretical model, consequently, ability of shaping current by using CSC was successfully simulated for DCM and CCM, as well as postfitting current matching technique was successfully applied during the transition between different voltage levels of single-phase three-level NPC converter.

The real experiment would require the improvement of CSC by including conduction loses of real switching and reactive elements. Additionally, post- or pre-fitting techniques should be dynamically selected in order to have fluent change of duty cycle value.

\section{ACKNOWLEDGEMENT}

This research work has been supported by Latvian Council of Science (Grant 673/2014 and Grant 416/2012). 


\section{REFERENCES}

[1] T. Qi, L. Xing, and J. Sun, "Dual-Boost PFC Converter Control Without Input Current Sensing," in 2009 Twenty-Fourth Annual IEEE Applied Power Electronics Conference and Exposition, 2009, pp. 1855-1861. http://dx.doi.org/10.1109/APEC.2009.4802923

[2] F. Javier Azcondo, A. de Castro, V. M. Lopez, and O. Garcia, "Power Factor Correction Without Current Sensor Based on Digital Current Rebuilding," IEEE Trans. Power Electron., vol. 25, no. 6, pp. 15271536, Jun. 2010. http://dx.doi.org/10.1109/TPEL.2009.2039231

[3] A. Garcia, A. de Castro, O. Garcia, and F. J. Azcondo, "Pre-calculated duty cycle control implemented in FPGA for power factor correction," in 2009 35th Annual Conference of IEEE Industrial Electronics, 2009, pp. 2955-2960.

[4] M. Rodriguez, V. M. Lopez, F. J. Azcondo, J. Sebastian, and D. Maksimovic, "Average Inductor Current Sensor for Digitally Controlled Switched-Mode Power Supplies," IEEE Trans. Power Electron., vol. 27, no. 8, pp. 3795-3806, Aug. 2012. http://dx.doi.org/10.1109/TPEL.2012.2183893

[5] H. Chen, "Single-Loop Current Sensorless Control for Single-Phase BoostType SMR," IEEE Trans. Power Electron., vol. 24, no. 1, pp. 163-171, Jan. 2009. http://dx.doi.org/10.1109/TPEL.2008.2006359

[6] H.-C. Chen, C.-C. Lin, and J.-Y. Liao, "Modified Single-Loop Current Sensorless Control for Single-Phase Boost-Type SMR With Distorted Input Voltage," IEEE Trans. Power Electron., vol. 26, no. 5, pp. 13221328, May 2011. http://dx.doi.org/10.1109/TPEL.2010.2070079

[7] W. Zhang, S. Member, G. Feng, Y. Liu, and S. Member, "A Digital Power Factor Correction ( PFC ) Control Strategy Optimized for DSP," vol. 19 , no. 6 , pp. 1474-1485, 2004.

[8] H. Chen and J. Liao, "Bidirectional Current Sensorless Control for the Full-Bridge AC/DC Converter With Considering Both Inductor Resistance and Conduction Voltages," vol. 29, no. 4, pp. 2071-2082, 2014.

[9] A. Suzdalenko, "Current Sensorless Control of Front-end Bidirectional AC/DC Converter Based on Half-bridge Topology," Electr. Control Commun. Eng., vol. 4, no. 1, pp. 19-25, Jan. 2013.

[10] A. Suzdalenko, "Development of Single-Switch Model for Current Sensorless Control of Bidirectional Half-bridge AC / DC Converter," in Proceedings of the 55th International Scientific Conference on Power and Electrical Engineering of Riga Technical University (RTUCON), 2014, vol. 24, no. c, pp. 38-42.

[11] B.-R. Lin and H.-H. Lu, "Multilevel AC/DC/AC converter for AC drives," IEE Proc. - Electr. Power Appl., vol. 146, no. 4, p. 397, 1999. http://dx.doi.org/10.1049/ip-epa:19990253

[12] J. Rodriguez, S. Bernet, B. Wu, J. O. Pontt, and S. Kouro, "Multilevel Voltage-Source-Converter Topologies for Industrial Medium-Voltage Drives," IEEE Trans. Ind. Electron., vol. 54, no. 6, pp. 2930-2945, Dec. 2007. http://dx.doi.org/10.1109/TIE.2007.907044

[13] U. Zlwk, H. Dqg, H. Dq, U. Vhplfrqgxfwru, G. Frvw, X. S. Wr, V. Zlwk, W. K. H. Sursrvhg, G. Duh, and E. Uhylhzhg, "Design, modeling, and control of multilevel converter motor drive with modular design and split winding machine," in 2014 IEEE 15th Workshop on Control and Modeling for Power Electronics (COMPEL), 2014, vol. 203, pp. 1-10.

[14] C. Roncero-Clemente, E. Romero-Cadaval, O. Husev, D. Vinnikov, and S. Stepenko, "Simulation of Grid Connected Three-Level Neutral-PointClamped qZS Inverter using PSCAD," Electr. Control Commun. Eng., vol. 2, no. 1, pp. 14-19, Jan. 2013.

[15] P. Mlodzikowski, A. Milczarek, and M. Mainoski, "Application of Simplified Neutral Point Clamped Multilevel Converter in a Small Wind Turbine," Electr. Control Commun. Eng., vol. 5, no. 1, pp. 5-10, 2014.

[16] S. Calligaro, F. Pasut, R. Petrella, and A. Pevere, "Modulation techniques for three-phase three-level NPC inverters: A review and a novel solution for switching losses reduction and optimal neutral-point balancing in photovoltaic applications," in 2013 Twenty-Eighth Annual IEEE Applied Power Electronics Conference and Exposition (APEC), 2013, pp. 2997-3004. http://dx.doi.org/10.1109/APEC.2013.6520725

[17] F. Sebaaly, H. Y. Kanaan, and N. Moubayed, "Three-level neutral-pointclamped inverters in transformerless PV systems - State of the art," in MELECON 2014 - 2014 17th IEEE Mediterranean Electrotechnical Conference, 2014, no. April, pp. 1-7.
[18] M. Sprenger, T. Barth, R. Alvarez, M. Tannhaeuser, and S. Bernet, "Experimental verification of direct dead-time Control and DC-link neutral-point balancing of a three level neutral-point-clamped (3L-NPC) VSC," in 2013 IEEE Energy Conversion Congress and Exposition, 2013, no. 3, pp. 409-413.

[19] P. Stolze, P. Karamanakos, M. Tomlinson, R. Kennel, T. Mouton, and S. Manias, "Heuristic variable switching point predictive current control for the three-level neutral point clamped inverter," in 2013 IEEE International Symposium on Sensorless Control for Electrical Drives and Predictive Control of Electrical Drives and Power Electronics (SLED/PRECEDE), 2013, no. Im, pp. 1-8.

[20] C. Roncero-Clemente, E. Romero-Cadaval, O. Husev, and D. Vinnikov, "Simulation Study of Different Modulation Techniques for Three-Level Quasi-Z-Source Inverter," Electr. Control Commun. Eng., vol. 1, no. 1, pp. 11-17, Jan. 2012.

[21] J. I. Leon, R. Portillo, S. Vazquez, J. J. Padilla, L. G. Franquelo, and J. M. Carrasco, "Simple Unified Approach to Develop a Time-Domain Modulation Strategy for Single-Phase Multilevel Converters," IEEE Trans. Ind. Electron., vol. 55, no. 9, pp. 3239-3248, Sep. 2008. http://dx.doi.org/10.1109/TIE.2008.928141

[22] B.-R. Lin and T.-C. Wei, "Current sensorless three-phase NPC converter with less power switches," IEE Proc. - Electr. Power Appl., vol. 150, no. 5, p. 555, 2003. http://dx.doi.org/10.1049/ip-epa:20030489

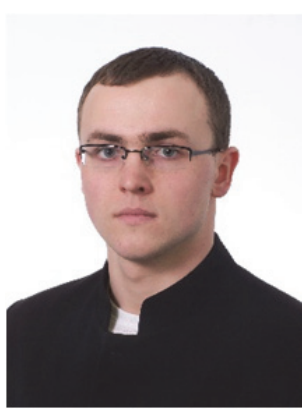

Alexander Suzdalenko received $B$. Sc. (2007), M. Sc. (2009) and Dr. sc. ing. (2013) degree from Riga Technical University in the field of electrical engineering. His research interests are related to design and control of power electronic converters. He contributed to intelligent household energy systems, studying the power balancing approaches, non-intrusive load monitoring algorithms and advantages of usage of LEDs.

He acquired practical experience working for two years in scientific and production association ELLAT Ltd as electronic device engineer.

$\mathrm{He}$ is a IEEE member since 2010 and joined PELS, IES and IAS societies. E-mail: Aleksandrs.Suzdalenko@rtu.lv

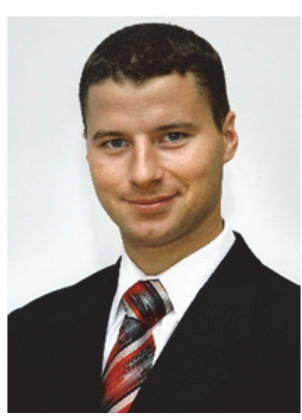

Janis Zakis (M'10 - SM'14) received B. Sc., M. Sc. and Dr. sc. ing. in electrical engineering from Riga Technical University, Riga, Latvia, in 2002, 2004 and 2008, respectively.

$\mathrm{He}$ is presently a Senior Researcher with the Institute of Industrial Electronics and Electrical Engineering, Riga Technical University.

He has over 20 publications and is the holder of the Utility Model in power converter design. His research interests include flexible ac transmission systems (FACTS), simulation of power systems, switching mode power converters, applied design of power converters and energy storage systems.

Address: Institute of Industrial Electronics and Electrical Engineering, Riga Technical University, Azenes 12/1, LV-1048 Riga, Latvia;

E-mail: janis.zakis@rtu.lv, janis.zakis@ieee.org

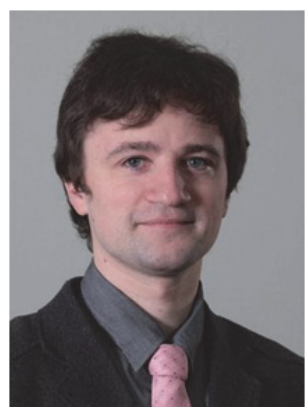

Ingars Steiks received B. sc. ing., M. sc. ing. and $D r$. sc.ing. degrees from the Faculty of Power and Electrical Engineering, Riga Technical University, Riga, Latvia, in 2003, 2005 and 2011 respectively.

Since 2006, he has been a Researcher with the Institute of Industrial Electronics and Electrical Engineering, Riga Technical University.

His main research interests include modular multilevel power converter applications for fuel cells. He is a Student Member of the IEEE Industrial Electronics Society since 2006.

E-mail: Ingars.Steiks@rtu.lv 